\title{
The impact analysis for marine environment caused by the thermal discharge of power plant
}

\author{
SHANG Jiang ${ }^{1, a^{*}}$ and JIANPING Hou ${ }^{1, b}$ \\ ${ }^{1}$ Third Institute of Oceangraphy,SOA,Xiamen,Fujian,China \\ ajiangshang@tio.org.cn, b383406119@qq.com
}

Keywords: thermal discharge; phytoplankton; zooplankton; benthic organisms; red tide

Abstract. Nuclear power is a clean and efficient energy, the development of nuclear power not only to meet energy needs, but also is an effective solution to the problem of the growing air pollution and greenhouse gas emissions. Maximum pollution is thermal pollution which generated by nuclear power operators, namely thermal discharge emissions. The temperatures of drainage outfall are generally exceed above $7^{\circ} \mathrm{C}$ than the marine environment temperatures, the elevated temperature continued to spread and lower through the exchange of the cooling water flow. The up temperature might be has ecological impact on the marine environment and marine life surrounding. The article analysis the influences on plankton, benthos, fish and red tide of water body by the thermal discharge through a coastal nuclear power plant as an example.

\section{INTRODUCTION}

Type area. Luoyuan Bay power plant is located in the Luoyuan Bay of Fuzhou port door operation area, the proposed $2 \times 1000 \mathrm{MW}$ ultra supercritical condensing coal-fired generating units, the annual power generation of about $1 \times 10^{10} \mathrm{kwh}$. The project adopts direct seawater cooling way, summer water is about $60 \mathrm{~m} 3 / \mathrm{s}$. Engineering intake arrangement on the shore; the power plant cooling water drainage outlet is arranged on the south-west corner, from the drainage port into the power plant on the west side of the drainage channel.Cooling water discharge will cause temperature rise near the sea outfall, have a certain impact on the temperature of the oceans, marine ecology and marine aquaculture. This paper uses mathematical model method to study the effect of warm water drainage on the marine ecosystem.

The mathematical model. The tidal current field equation of two-dimensional active shallow water equations plane rectangular coordinates.

$$
\frac{\partial \eta}{\partial t}+\frac{\partial}{\partial x}(H u)+\frac{\partial}{\partial y}(H v)=q
$$

Momentum equation of $\mathrm{X}$ direction:

$$
\frac{\partial u}{\partial t}+u \frac{\partial u}{\partial x}+v \frac{\partial u}{\partial y}=-g \frac{\partial \eta}{\partial x}+f v-r u+A_{x}\left(\frac{\partial_{u}^{2}}{\partial_{x}^{2}}+\frac{\partial_{u}^{2}}{\partial_{y}^{2}}\right)+M_{x}
$$

Momentum equation of $\mathrm{Y}$ direction: 


$$
\frac{\partial v}{\partial t}+u \frac{\partial v}{\partial x}+v \frac{\partial v}{\partial y}=-g \frac{\partial \eta}{\partial y}-f u-r v+A_{y}\left(\frac{\partial_{v}^{2}}{\partial_{x}^{2}}+\frac{\partial_{v}^{2}}{\partial_{y}^{2}}\right)+M_{y}
$$

Of which: $x, y$ for plane rectangular coordinates; $t$ for the time; $H$ is the depth of water $(H=d+\eta) ; d$ is the average water level plane under the water depth; $\eta$ is water level; $u 、 v$ respectively $x, y$ direction component, $u=(1 / H) \int_{-h}^{\eta} u^{\prime} d z$ and $v=(1 / H) \int_{-h}^{\eta} v^{\prime} d z$ the depth average flow velocity; $g$ for the acceleration of gravity, $f$ is Coriolis parameter, $r$ as the bottom friction coefficient,and $c_{n}$ as the Chezy coefficient, $n$ for the seabed roughness coefficient, according to different regional value, about $0.017 \sim 0.023 . A_{x} 、 A_{y}$ is the level of kinematic viscosity coefficient, using Smagorinsky formula.

Based on considering the water intake and drainage boundary flow of tidal current field, two-dimensional temperature field equation:

$$
\frac{\partial T}{\partial t}+u \frac{\partial T}{\partial x}+v \frac{\partial T}{\partial y}=-\frac{K T}{H \rho C_{p}}+\frac{1}{H}\left\{\frac{\partial}{\partial x}\left(D_{x} \frac{\partial T}{\partial x}\right)+\frac{\partial}{\partial y}\left(D_{y} \frac{\partial T}{\partial y}\right)\right\}+Q_{0}
$$

Among them: $T$ for the water along the depth averaged temperature rise $\left({ }^{\circ} \mathrm{C}\right), K$ is diffusion coefficient for the comprehensive heat water; $D_{x} 、 D_{y}$ respectively $x, y$ the direction of turbulent heat diffusion coefficient; $C_{p}$ is specific heat; $\rho$ is the density of water; $Q_{0}$ discharge source.

\section{Model validation}

Luoyuan Bay and adjacent sea area calculation of tidal current field simulation provide offshore boundary condition by the Taiwan Strait tidal wave model. In order to check the reliability of tidal current field calculation in Luoyuan Bay and its adjacent waters, tidal current field, verify the tide, tidal current.

The measured data using the 2012 March tide flow measurement and synchronization of tidal level and tidal current site measured data.

Tidal level verification Figure 1 for the XIAGONG tidal flow measurement station during the tide level calculation with the measured values, the results show that the calculated values agree well with the measured values of tidal curve.

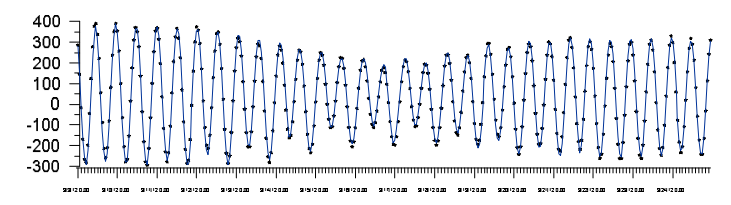

Figure 1. Tidal level validation curve of XIAGONG 


\section{The influence scope of thermal discharge}

This project is located in the South Bank of the power plant in Luoyuan Bay, thermal discharge into the sea after the diffusion along the coastline, and parallel to the direction of the power plant is basically along the downstream waters, lateral diffusion distance is much larger than the longitudinal diffusion distance offshore, The whole tidal maximum temperature rise envelope show that, most of the rise in temperature near the sea outfall is less than $2^{\circ} \mathrm{C}$. of more than $2^{\circ} \mathrm{C}$ temperature rise the envelope is concentrated in drains near the exit of local waters.

The project of power plant water depth is larger, drains outside the East water depth basically is in $20 \mathrm{~m}$ above, drains the outer West depth basically also is in $10 \mathrm{~m}$ above, diffusion conditions better than Kemen power station, the temperature rise of the small door power plant.

Different type of tide, tide, diffusion ability, high temperature zone near the area of the drainage port is easy to spread, the far zone temperature rise zone along the transverse direction diffusion is relatively far away from the. Neap tides and $97 \%$ minimum tidal range, low temperature rise zone along the lateral diffusion capacity is relatively weak, the high temperature rise of longitudinal diffusion is relatively far away from the shore.

When the warm water drainage quantity is $60 \mathrm{~m}^{3} / \mathrm{s}$, the Area of temperature rise more then $1^{\circ} \mathrm{C}$, $2^{\circ} \mathrm{C}, 3^{\circ} \mathrm{C}, 4^{\circ} \mathrm{C}$ respectively is $2.555,0.992,0.595$ and $0.412 \mathrm{~km}^{2}$. Figure 2 . For the whole spring tidal maximum temperature rise envelope.

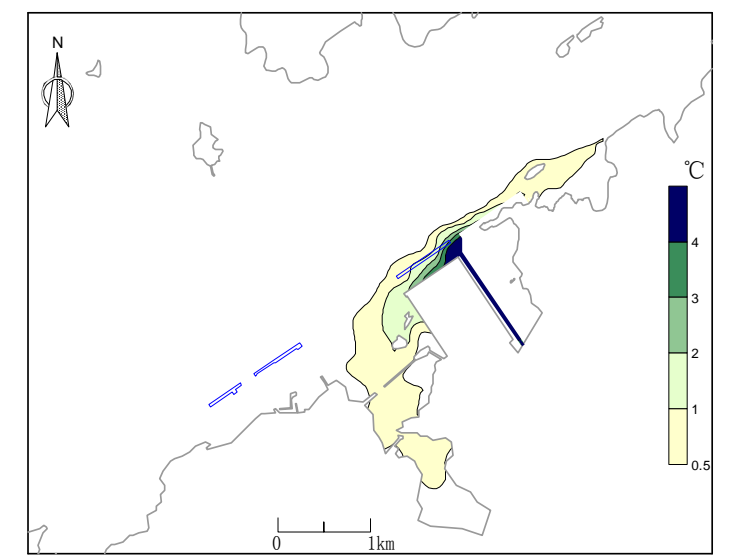

Figure 2. The whole spring tidal maximum temperature rise envelope

\section{The impact analysis for marine environment of thermal discharge}

The impact on plankton by thermal discharge. Thermal effects of cooling water will change the status of the local natural sea water, a large number of studies have shown: water warming affected on the growth of planktonic algae, species composition, dominant species, the influence depth related to the environmental temperature and warming magnitude. When ambient temperature is low, warming the water body can promote the growth of algae. Moreover the algae growth along with the incremental temperature increases; When ambient temperature is moderate, weak warming and the warming zone ( (temperature rise $\left.\leq 3^{\circ} \mathrm{C}\right)$ can promote algae growth, while strong warming (temperature rise $>3^{\circ} \mathrm{C}$ ) will inhibit the growth of algae; When ambient temperature is high, warming the water will inhibit the growth of algae, the greater the magnitude of warming, the stronger the effect of inhibiting addition, the water temperature also have an impact on the species composition of phytoplankton.DU Xiao-Ming and somebody else did investigation on the thermal discharge influence which caused by thermal power plant, the field survey data and indoor simulated warming results showed that: (1) water temperature $<25^{\circ} \mathrm{C}$, the water warming in favor of algae growth; environmental temperature $>25^{\circ} \mathrm{C}$, the increase temperature inhibition on algae 
growth (except cyanobacteria); temperature is above $30^{\circ} \mathrm{C}$, the moved forward warming water can drastically reduce the population of algae; (2) The density of algae in different areas of warming during the four seasons is different. In Spring, the density of algae as this: strong warming temperature zone $\left(5^{\circ} \mathrm{C} \sim 6^{\circ} \mathrm{C}\right)>$ weak warming zone $\left(2^{\circ} \mathrm{C} \sim 3^{\circ} \mathrm{C}\right)>$ natural environment zone; In Summer, natural environment zone > weak warming zone $\left(2^{\circ} \mathrm{C} \sim 3^{\circ} \mathrm{C}\right)>$ strong warming zone $\left(5^{\circ} \mathrm{C} \sim\right.$ $\left.6^{\circ} \mathrm{C}\right)$; In Autumn, weak autumn warming zone $\left(2^{\circ} \mathrm{C} \sim 3^{\circ} \mathrm{C}\right)>$ strong warming zone $\left(5^{\circ} \mathrm{C} \sim 6^{\circ} \mathrm{C}\right)>$ natural environment zone, indicating that if the water temperature is low, water warming can stimulate algal reproduction largely, but it is harmful to the growth of algae when water temperature is high naturally.

Heat emissions also affect zooplankton number, type and diversity. Jin La Hua etc. recognize that $\mathrm{t}$ strong warming in the water when the (temperature rise $>3^{\circ} \mathrm{C}$ ), aquatic biomes began to decline, especially in the summer when natural water temperatures higher in strong warming zone, means the water temperature exceeds $35^{\circ} \mathrm{C}$, the type and quantity of zooplankton will reduce, especially the number of some species significantly reduced, meanwhile the number of some species which can bear heat began to increase; when the water has moderate warming (temperature rise $\leq 3^{\circ} \mathrm{C}$ ), zooplankton average increase of 76\%.Jin Qiong Bei etc. investigations shows: Weak warming has good promotion on the increase for the number, species and diversity of zooplankton; strong warming zone $\left(31 \sim 39.6^{\circ} \mathrm{C}\right)$, it make decrease the number, species and diversity of zooplankton decreased. Jin Qiong Bei et studied to the zooplankton in the adjacent waters which nearby Liaoning power plant, the indoor simulation experiments showed that when the water temperature exceeds $30^{\circ} \mathrm{C}$, the number of copepod populations significantly reduced with increasing temperature.

According to the analysis of water quality status quo assessment area survey and historical data, the survey period evaluation in spring season average water temperature of about $21.8^{\circ} \mathrm{C}$, the summer average temperature is about $29.45^{\circ} \mathrm{C}$, the annual average temperature at about $19^{\circ} \mathrm{C}$. Therefore, can be predicted in the sea water temperature is low and relatively low in spring and autumn, winter three season, the warm water of power plant unit of this period, plankton species near the sea outfall of the density and biomass were certain promoter action, but in summer, warm water drainage discharge will be on temperature rise within the area of plankton species the composition, quantity and community structure will produce certain negative effects, especially the temperature higher than $4^{\circ} \mathrm{C}$ (maximum temperature envelope area of $0.412 \mathrm{~km}^{2}$ ) sphere of influence, impact on the plankton species composition, community structure and the quantity of the larger.

Effects on benthic organisms. Benthonic animal inhabit in the surface of the bottom sediment or shallow of sediments long time, they are relatively fixed and with weak migration, so they easy to be adversely affected instead of avoiding the thermal discharge impaction. Hu Deliang etc. noted that the adverse effects on benthic organisms comes by the thermal discharge of power plant mainly as following: high warming zone (temperature rise $>6^{\circ} \mathrm{C}$ ) will reduce the benthic habitats; warming in the hot season from July to September will make index of the benthic animal abundance and biodiversity fell; While the season with natural water temperature below $26^{\circ} \mathrm{C}$, the warming zone which with temperature rise $<3^{\circ} \mathrm{C}$, benthic species and number of animals to be rich than natural water bodies, the diversity index increased accordingly. Wang You Zhao etc. who study ecological environment changes of water which nearby Daya Bay Nuclear power plant, it showed that the water outfall nearby the Daya Bay nuclear power plant already impacted by thermal discharge, the benthic biomass decreased, diversity is also reduced.Within a certain temperature range, the lower the natural temperature, moderate warming will be more favorable on increase in the number, 
diversity index and species of. Since benthic animals are weak movement. strong warming zone (temperature rise $>3^{\circ} \mathrm{C}$ within the scope of) the biomass of benthic organisms will fall significantly, diversity is also significantly reduced benthic biomass and biological population structure will change significantly; when the temperature rise range (within $1{ }^{\circ} \mathrm{C} \sim 3^{\circ} \mathrm{C}$ ) it will affect the benthic biological population structure changes slowly; little effect on benthic organisms if within $1^{\circ} \mathrm{C}$ temperature rise.

Impaction on fish. Fish are cold-blooded animal, usually within the optimal temperature range; the water temperature rise will promote the growth of fish. But if it exceeds fish's optimum temperature range, some fish will be in varying degrees of impact on the breeding, embryonic development, fry survival, suppression fish metabolism and growth; beyond its limits to endure, fish will be lead to death. On the other hand, juvenile and adult fish can feel faint water temperature changes in the environment, to exceed the temperature range of high temperature (beyond their favorite temperature $1 \sim 3^{\circ} \mathrm{C}$ ) or cold water, they have the avoidance response, this phenomenon make a juvenile and adult fish avoid heat threats in the summer. In addition, the water temperature changes will affect fish spawning, changes in fishing season sooner or later and fishing grounds.

In surface water, temperature is the most important environmental factors affecting fish distribution. After the heat discharged into the water bodies, will change in fish and other aquatic organisms normal distribution in the water, causing changes in community structure. Effects different by different warming zones, usually when warming magnitude $>3^{\circ} \mathrm{C}$ is obvious harmful to some fish, such as the silverside fish larvae of water which nearby Daya Bay Nuclear Power Plant are disappear, quickly reduce the number of perch, changes in the population will exhibit some lag effect; warming magnitude $<3^{\circ} \mathrm{C}$ for fish showed a beneficial effect, with a range of populations and improve water temperature and fish move into increased emigration to reduce, which also increases the number of individuals. Some studies show that, thermal emissions affect fish spawning activity is obvious on adjacent waters, but has little effect on the survival and distribution of larvae. Fish generally avoid spawning in these waters which tend to rise above $1.0^{\circ} \mathrm{C}$ but choose the heat emission in the edge region ( temperature rise $1.0^{\circ} \mathrm{C}$ ) to spawning. Influence for eggs mortality by thermal emissions was not significant, the results of this study is consistent with Japan 's Environment Institute of Marine Biology .

Chinese Academy of Fishery Sciences did acute thermal shock test, hot avoidance test, the maximum initial lethal effects of temperature and constant heat test with 65 species sampling from several major Chinese river fish and aquatic animals, and then got result about the standard temperature for fishery waters which comes by the waste drainage to the Chinese fishing water. They thought that in the Summer of China, the highest temperature which comes by waste heat drainage should be as following: the coastal waters of Pearl River and Zhanjiang shall not exceed $36^{\circ} \mathrm{C}$; Yangtze and Qiantang River, the Yellow River should not exceed $35^{\circ} \mathrm{C}$; the coastal waters of Dalian Bay shall not exceed $24^{\circ} \mathrm{C}$, etc., and the maximum water temperature ranges for each river can not change exceed $\pm 3^{\circ} \mathrm{C}$. The above analysis that when the temperature rise above $3^{\circ} \mathrm{C}$, the potential ecological impact of emissions is harm to fish obviously, if rise below $3^{\circ} \mathrm{C}$ the number of the population increased with water temperature rise.

According to the research American Florida Bisayne Bay power plant cooling water, environmental water temperature reaches $32^{\circ} \mathrm{C}, 80$ species of fish have half will disappear; up to $36^{\circ} \mathrm{C}, 75 \%$ species have disappeared; the temperature is 3 to $4^{\circ} \mathrm{C}$ region, summer catch is very low, and the winter has been restored, but the average annual catches were still lower than the control station; rise $2 \sim 3^{\circ} \mathrm{C}$ in summer low temperature region, catch, but spring, winter high catch, catch the overall in the region higher than the annual average catch; in the temperature rise below no 
statistical difference of $2^{\circ} \mathrm{C}$ region and between control station.

According to the monitoring survey data, the survey period evaluation in spring season average water temperature of about $21.8^{\circ} \mathrm{C}$, the summer average temperature is about $29.45^{\circ} \mathrm{C}$, the annual average temperature at about $19^{\circ} \mathrm{C}$. At the same time by the ecological investigation shows that waters in warm water fish species system mainly in 53 kinds of fish catches, warm water species 33 species, accounting for $62.3 \%$, the warm temperate species 20 species, accounting for $37.7 \%$. Therefore, in addition to summer can predict this power plant phase is lower than $2^{\circ} \mathrm{C}$ temperature zone still in fish suitable temperature range, obvious influence on the growth of the fish will not, but may have a certain impact on fish spawning behavior and the community structure of fish (fish from abnormal activity to death the average temperature is $3^{\circ} \mathrm{C}$ ). For most warm warm temperature fish or fish, summer (7 9months) caused by the warm water drainage temperature $1^{\circ} \mathrm{C}$ basically in fish adaptation range, generally will not affect growth of fish; but the summer is greater than $3^{\circ} \mathrm{C}$ temperature zone especially temperature outlet near the water temperature may exceed

$36^{\circ} \mathrm{C}$ (super $4^{\circ} \mathrm{C}$ maximum temperature rise envelope area of $0.412 \mathrm{~km}^{2}$ ), more than most evaluation of sea fish suitable temperature, most fish will avoid temperature field.

The potential impact on the occurrence of red tide. The study shows that the warming could lead to the occurrence of red tide about water, probably due to two aspects: First, the warming can promote the decomposition of organic matter, so that the concentrations of the water inorganic nutrient increased; Second, warming accelerate the phytoplankton breed, especially the thermophilic blue-green algae.

The complexity of the mechanism of red tide, only occur when the conditions be provided in the chemical, biological and physical.1)biological conditions: the region needs the benthic cysts and organisms cells of red tide, and the the dominant populations formation through interspecific competition;(2)chemical conditions: the nutrients of the water (primarily nitrogen and phosphorus salt), the form and concentration of the trace elements and some special presence of organic matter, which can meet the needs of a large proliferation for red tide organisms; 3physical conditions (hydrology and meteorology): Water stable, low water exchange rate, rising presence of streams, suitable water temperature and salinity, wind, wind direction, temperature, sunlight intensity, rainfall and fresh water injection are all external conditions to incur red tide and make it continuation. In addition, studies show that red tide occurrence may also be related to global warming.

From this investigation, the species composition of phytoplankton in Skeletonema costatum (Skeletonema costatum) in this area the most widely distributed, is the first dominant species, the average density of $40.02 \times 10^{2}$ cells/L surface. Skeletonema costatum is a eurythermal and euryhaline nearshore of diatoms, when water temperature is 0 to $37^{\circ} \mathrm{C}$, salinity is $\mathrm{L} 3 \sim 36$ range can be growth, but the optimal proliferation of temperature and salinity range is 24 to $28^{\circ} \mathrm{C}$ and $20 \sim 30$. The ecotype could be divided into North and south, Yangtze River Estuary this kind of intensive at about $25^{\circ} \mathrm{C}$, the salinity is $14 \sim 20$ in the summer, is a common red tide. You can think of has been red tide occurring in Skeletonema costatum in density exceeds $5000 / \mathrm{mL}$, a sheet or band of uneven distribution on the surface of the water and aquifer, water showed yellowish brown, with the occurrence of red tide algae smell, process and Noctiluca scintillans alternating became dominant species. This species of red tide and non-toxic, the proliferation rate very fast, such as nutrient sufficient, hydrological and meteorological conditions are relatively stable, can form the breeding peak in spring, summer, autumn 3 season. Higher sensitivity of red tide. Skeletonema costatum is one of the most common area of East China Sea red tide organisms, was recorded 19 times the initiator of the red tide. The influence of the thermal analysis combined with drainage of 
phytoplankton, may think that the development of power plant cooling water to nearby waters eutrophication will play a certain role in promoting, especially in spring and autumn, near the sea outfall eutrophication development is more sensitive to temperature and drainage.

Taking into account that the suitability of sea water temperature is an important environmental factor to make the red tide organisms to survive and reproduce, during the operations of Nuclear Power plant, the cycle of drainage waters can make partial sea temperature has increased, therefore, recommended to strengthened supervising for water temperature and red tide of the sea area which nearby the thermal discharges of power plant during Nuclear Power Plant operations.

\section{Conclusions}

The area maximum temperature rise at $3^{\circ} \mathrm{C}$ which caused by the thermal discharge of Nuclear power. Within this range, the plankton, fish species and catches may be affected; the early larval growths of the shrimp, crabs may be inhibited. But outside this area of the water drain, if water temperature rise less than $3^{\circ} \mathrm{C}$ or other seasons except Summer, the thermal discharge of the nuclear power plant will promote the growths and reproductions of plankton, fish and crustacean on some extent. During the operations of Nuclear Power Plant, they should keep track of the situation of marine biological and ecological, then can make sure the fact lost on marine biology and fisheries resources which caused by the thermal discharge of Nuclear Power Plant.

\section{References}

[1] Casulli V. \& Cheng R T. 1992,Semi-implicit finite difference methods for three-dimension shallow water flow. International Journal for Numerical in Fluids 15:629 648.

[2] Casulli,V, \&Cattani,E. 1994, Stability, accuracy and efficiency of a semi-implicit method for three-dimension shallow water flow. Computer Math Applic 27(4) :99 112.

[3] Hamrikc,J.M. 2000,Analysis of water temperature in Conowingo pond as influenced by the peach bottom atomic power plant thermal discharge. Environmental Science \&Policy 30(5):126-131

[4] Hao,Q.Z. \&JIA,L.2011, The Environmental Impact and Intake Water Temperature Analysis of Cooling Water in Coastal Power Plant. Electric Power Construction 32(2):6-9.

[5] Wen,S.H. \&Cai,S. 2003, Three-Dimensional Hydrodynamic Model of Xiamen Waters.Acta Oceanologica Sinica 22(2): 151 169. 